\title{
APPROVED PROJECTS TO BE FUNDED BY THE EQC RESEARCH PROGRAMME 1993/4
}

\begin{abstract}
It has recently been announced by the Earthquake and War Damage Commission that the following research projects are to be funded from the EQC Research budget for 1993/94. The summaries given below are the abstract or summary included in the research application.
\end{abstract}

\section{SE 102 Retrofitting of Existing Reinforced Concrete Building Frames \\ University of Canterbury - Prof R Park}

Typical early reinforced concrete building structures, designed according to building codes prior to about 1970, have reinforcing details which are adequate for gravity and wind loads but may not be adequate for earthquake loads. Earthquake design codes before about 1970 did not specify capacity design nor detailing procedures which ensure adequate strength and ductility in the event of a major earthquake. A typical reinforced concrete building which was designed in Christchurch in the late 1950's has been assessed. It has been shown that with regard to earthquake resistance the columns have inadequate longitudinal reinforcement for flexural strength and inadequate transverse reinforcement for shear strength and ductility, and that the beams and beam-column joints have inadequate transverse reinforcement for shear resistance. To date, two near full scale replicas of the columns and the interior beam-column joints of the building have been tested under simulated seismic loading in the Structures Laboratory to establish their performance in a major earthquake. Retrofitting methods have been devised and are being tested.

The aim of the project is to conduct further tests on a range of poor reinforcement details typical of some early existing reinforced concrete frames, to obtain additional information for the seismic assessment of existing structures.

\section{SE 103 Precast Concrete Floor Unit Support and Continuity University of Canterbury - Prof $R$ Park}

In New Zealand the use of precast concrete flooring systems in buildings has become commonplace, leaving cast in place concrete floor construction generally uncommon. While design and construction aspects for precast floors have generally been carefully considered, aspects of floor support (seating) and continuity in building structures designed for seismic loading have not been covered by New Zealand or overseas standards. In February 1988, a seminar at the
University of Canterbury attended by designers, researchers, fabricators and constructors, highlighted a growing need to investigate and verify the performance of precast concrete in building structures designed for seismic resistance. As a result a Study Group of the NZ Concrete Society, the NZ National Society for Earthquake Engineering and the Centre for Advanced Engineering of the University of Canterbury was set up which resulted in the publication in 1991 of a manual entitled "Guidelines for the Use of Structural Precast Concrete in Buildings". The support (seating) of precast concrete floor systems was identified as a possible problem area in building design and construction.

The aim of the proposed research project is to obtain additional information on the performance of various possible methods for supporting precast concrete floors on beams in buildings designed for earthquake resistance. The information is expected to be of benefit and value to designers, contractors and checking authorities and should lead to improvements in the design and construction of support details.

SG 111 The Neotectonics of the Ruahine and Mohaka Faults between the Manawatu Gorge and Puketitiri Dept of Soil Science, Massey University - Prof VE Neall

The proposed study will involve:

1. Extensive interpretation of active faulting visible on aerial photographs of the Ruahine and Mohaka faults.

2. Locating trench and ponded drainage sites for radiocarbon dating of fault movements.

3. Mapping fault trace segments and determining offsets for each segment.

4. Using micro-(thin section) and macro-structural techniques to determine deformational history and neotectonic uplift of geological cover strata adjacent to the faults.

5. Tephra identification to date offset surfaces.

6. Creation of earthquake history along both faults during Holocene time, interpreting earthquake magnitudes and frequencies. 
SG 117 Observation and Synthesis of Seismic Wavefields in Basin Structures II

Inst of Geophysics, Victoria University - Prof J Ansell

In the first part of this project the computational techniques developed by Dr Haines and Dr Benites (IGNS) have been used to synthesize seismic wavefields in some sample 1 as in structures. The computations have been compared with exact analytic solutions and an understanding of the nature of the shaking has been developed.

The projected work involves the analysis of seismic wavefields to identify components which are systematic and those that are essentially random or chaotic. This will be done for both for IGNS seismic field datal from a closely spaced array on a small "simple" basin, and for an extensive data-set of theoretical wavefields for Christchurch Central, computed by Dr A.J. Haines. VUW field observations from Christchurch recorded by Dr I Taber will also be available. A procedure to extract useful and usable information from complex observed and theoretical wave fields will be developed, using the understanding developed in part I of the project.

SG 118 Imaging of the 3-dimensional Structure of the Subduction Zone, Southern North Island Inst of Geophysics, Victoria University - Prof J Ansell

A newly developed 3-dimensional seismic tomographic technique will be used to obtain a more detailed image of the structure in the southern North Island. The technique will invert a very large quantity of seismic arrival time data from local and regional earthquakes, recorded at stations in this region. A three dimensional picture of the subduction zone and overlying crust will emerge.

A very large data-set will be available from the national seismograph network, the Wellington network, a temporary VUW network, the POMS network (Leeds Univ, VUW) and the very extensive forthcoming PANDA network (Memphis State Univ, IGNS, VUW).

Three dimensional ray-tracing will be used to determine the shape of the interface between the Pacific and Australian plates and also the velocity structure in this region of potentially very large earthquakes (c.f. Robinson, 1987; Ansell and Bannister, 1991; Galea, 1991). The role of the interface may be critical in the largest earthquakes, but it is not clearly understood (Darby and Beanland, 1992). The structure found by this study should assist in that understanding.

SG 120 Quantification of Seismic Shaking Variations due to Source Effects at Soft Soil Sites in the Wellington Region

Inst of Geophysics, Victoria University - Mr JJ Taber

The process by which flexible sediment motion is amplified in sedimentary basins is still not well understood. Recordings of microearthquakes show a wide range of amplifications at the same site for different earthquakes depending on the location and mechanism of the earthquake. To understand basin response, it is necessary to quantify the relationship of the input motion measured at a rock site to the resulting motion in the basin. As examples of site response in sedimentary basins, site effects in the Wellington region from micro-earthquakes will be quantified to isolate the important variables governing the shaking. These results will be compared with synthetic ground motions computed by a three-dimensional modelling technique.

An excellent data set has already been collected by VUW for over 50 urban sites (with up to 15 earthquakes per site) in the Wellington region. The average characteristics of these sites has been studied, but directional effects and variations of amplitude depending on the earthquake source have not been considered, beyond noting the existence of the variations. The 3 -component data allow particle motions to be analysed for any direction, so the directions of maximum or minimum excitation can be found. The site responses range from strong resonances over a narrow frequency band for sites on shallow, flexible sediments to broad band amplification on thick soils and gravels.

SG 128 An Investigation of Latest Displacement Events on the Wellington Fault in the Lower Hutt Area Ian R Brown Associates Lid - Dr I Brown

Recent geological studies carried out for Wellington Regional Council have provided data on displacement activity of the Wellington Fault, and evidence for a $75 \mathrm{~km}$ fault rupture segment from Cook Strait to the Upper Hutt area (known as the Wellington Hutt Valley Segment). Interpretations of fault activity and displacement rates are largely based on data from the two ends of the segment, with limited data from the central part. Over a period of several years, Ian R Brown Associates Ltd have been involved in studies of the Wellington Fault in the area of The Hutt City. We have identified four locations along the Wellington Fault with vacant land which would be suitable for detailed trench investigations. At these sites we believe we will be able to obtain vertical and horizontal displacement data, and age relationships. Our proposal will involve detailed trench logging, selected sampling and radiocarbon dating which will constrain the timings of recent fault events in Lower Hutt. The results of this work will improve our existing geological and seismic hazard models for the Wellington Fault.

ES 130 Improved Components for the Seismic Isolation of Industrial Plant Industrial Research Ltd - Dr WH Robinson

Earthquake damage to expensive or strategic industrial plant can often be reduced by factors of 2 to 5 or more by the inclusion of seismic isolation. However, the well-developed isolation systems which are effective for buildings and bridges are less appropriate for the seismic isolation of industrial plant. Factors influencing the demands on industrial plant isolation systems include:

degree of vulnerability which is sometimes very high; often very low and sometimes irregular mass distribution

Earlier work by the Project Leader indicates that it is possible to develop more appropriate and cost-effective isolator components for industrial plant. 
GE 136 Seismic Liquefaction in the 1987 and 1992 Bay of Plenty Earthquakes

Dept of Civil Engineering, Canterbury University - $J_{B}$ Berrill

The liquefaction that took place in the sediments of the Rangitaiki Plains during the 1987 Edgecumbe earthquake is probably the most extensive in New Zealand's history, and caused about $\$ 10$ million of damage to drainage and flood control works alone. The aim of this project is firstly to document the liquefaction effects, including the amount $\sim \mathrm{f}$ lateral spreading, (following on from preliminary work by Bienvenu and Berrill, Stephenson and Barker, and Jennings immediately after the earthquake) and to investigate selected sites further with piezocone penetrometer testing and drilling, employing the University's Fugro piezocone and drilling rig. The data will then be used to check various empirical models for predicting liquefaction potential and lateral spreading distances, especially the University of Canterbury models of Davis and Berrill md the pattern recognition model of Dou, as well as the spreading models of Youd.

The occurrence of a small earthquake in June 1992 in the same area and which apparently did not cause any liquefaction at the 1987 sites greatly increases the value of these cases.

SG 139 Refining the Large Earthquake Hazard Estimate for the Wellington Region from a Reinter-pretation of Raised Beaches at Turakirae Head

IGNS - Dr A Hull

Estimation of the hazard to Wellington City from large earthquakes requires accurate quantification of the number, timing and magnitudes of past large earthquakes. The 1855 Wairarapa earthquake is the largest historic earthquake in New Zealand, and caused widespread damage to early settlements in central New Zealand. A clear understanding of the macroseismic and geologic effects of the 1855 earthquake is required if we are to understand the likely consequences of future large earthquakes near Wellington.

A series of historical misinterpretations led to confusion and misidentification of the location and elevation of the storm beach raised by the 1855 Wairarapa earthquake at Turakirae Head, south Wairarapa Our preliminary studies indicate that the beach ridge currently believed to have been uplifted up to $3 \mathrm{~m}$ in 1855 is the modern, still actively growing, storm beach at $2.5 \mathrm{~m}$ above mean sea level. The next beach up in the sequence at $6.5 \mathrm{~m}$ above the modem storm beach is the one that first was raised above the fetch of stormwaves during the 1855 earthquake. Thirteen radiocarbon dates $f$ rom within this raised beach indicate that it accreted gravel and shells from about $500 \mathrm{yr} \mathrm{BP}$ to $<250 \mathrm{yr} \mathrm{BP}$, and thus was an active and growing storm beach from ca $1450 \mathrm{AD}$ to 1855. Recently discovered well-preserved in situ remains of the uplifted intertidal fauna at the foot of this raised beach provide further datable material from which to confirm our hypothesis.

The proposed study will accurately determine the location and elevation of the 1855 storm beach and its associated remnants of pre-1855 intertidal zone uplifted during the 1855 Wairarapa earthquake and of other older storm beaches in the area of Turakirae Head. These data, together with new and existing radiocarbon dates will allow re-evaluation of the uplift distribution, possible earthquake magnitude of the 1855 Wairarapa earthquake, and the magnitude and frequency of past large earthquakes affecting the greater Wellington area.

\section{SG 140 The 1855 West Wairarapa Earthquake: Analysis of Historic Data IGNS/Victoria University - $G L$ Downes/R Grapes}

With a magnitude of about 8.2, the 1855 West Wairarapa earthquake is New Zealand's largest known earthquake since more extensive European settlement in 1840. There have been so few large, well observed earthquakes in the short seismological history of New Zealand that it is of importance to document the effects of such events for use in engineering design and the assessment of seismic hazard.

The Seismological Observatory holds many files on this earthquake which have been augmented by the extensive research of the late G. Eiby, and which now form part of the responsibilities of G. Downes. Further, R. Grapes has for a number of years been assembling historic data on the same event and has been studying the West Wairarapa Fault trace over the last four years.

Although some specific aspects of the effects of the earthquake have been published, there has been no comprehensive study of all the contemporary geological and seismological data available. It is known that there has been some confusion and misinterpretation in historic descriptions. It is now proposed to combine the Observatory data with that of Grapes, thus forming a valuable database containing most of the available source material. This data will be published and annotated, with notes on the credibility of the information. This will include portions from relevant contemporary official publications, diaries, personal papers, newspapers and relevant hydrographic charts. The New Zealand Journal of Geology and Geophysics has been approached and the editor is willing to devote an entire issue to the publication of the data in this form.

It is also expected that a summary of felt effects and an isoseismal map will be included and a summary of geologic effects in relation to the present day observable fault trace.

\section{SG 141 Statistical Modelling of MM Intensity Observations IGNS - Dr E Smith}

Accurate appraisal of NZ's historical seismicity depends on making the best use of felt intensity data, which are the only data available for about one-third of NZ's most important earthquakes.

This project will seek to model the distribution of individual observed MM Intensity values in a statistically rigorous way, leading to objectively determined isoseismals, and hence to 'attenuation' models for MM Intensity that have meaningful uncertainty estimates explicitly as part of the model.

The method will involve pilot studies of a few of the best observed larger earthquakes, certainly including Edgecumbe 1987 and Inangahua 1968, in which the locations of observed felt intensities will be entered into a computer database for analysis. This analysis will allow for the typical distribution 
of intensities within a small locality (a range of up to $4 \mathrm{MM}$ values), the likelihood of biased sampling of high intensities at a locality because of preferential historical reporting of 'worst cases', and the likelihood of non-isotropic attenuation.

The product will be an algorithm for (effectively) drawing isoseismals that takes the above into account. This algorithm will draw on existing contouring programmes for geophysical data that deal with very unevenly distributed observations by collocation weighting. The isoseismals will be reasonably constrained to be low-order curves (i.e., very wiggly isoseismals will be barred).

The future development of the project would allow consistent reinterpretation of felt intensity data of all NZ's largest earthquakes, leading in turn to better seismicity and attenuation models and more accurate hazard and risk assessments.

\section{SG 144 Synthetic Seismicity Models for the Wellington Region IGNS - R Robinson}

Because of the short historical record of seismicity in New Zealand hazard estimation is difficult. With recent advances in computer technology it is becoming possible to make physically reasonable models of earthquake occurrence and so extend the short historical record artificially. These models can take into account known mechanisms of strain accumulation and release, including the very important factor of interaction between fault segments, and are "tuned" to match the known historical record.

It is proposed to develop a model for the Wellington fault and to examine its implications for both long-term average and time-variable hazard estimation. The model would be extendible to include other faults as future resources allow. The dislocation methods for a segmented fault zone, developed at the University of California, Santa Cruz, would be adapted to a model of the Wellington fault with more realistic treatment of segmentation (e.g jogs or gaps) and strain accumulation. When a sufficiently realistic model is obtained, it would be used to simulate a long seismicity record, providing improved data for statistical hazard estimation. The model is likely to be "chaotic" and sensitive to boundary conditions, making predictions of specific large events imprecise, but the results would be used for testing various proposed methods of earthquake prediction based on seismicity patterns (e.g. quiescence, b-value changes, etc) as well as the effect of clustering of large events on hazard estimation.

\section{GE 150Seismic Ground Response Analyses of Pumiceous Sites Dept Civil Engineering, Auckland University - DrT J Larkin}

Experience from recent earthquakes has shown the importance of recognizing the effects of site geology on the intensity of surface motion during destructive earthquakes. In a number of instances building damage may be directly linked to the type and extent of the foundation geologic materials.

Recent research work has been carried out to evaluate the dynamic properties of some of the pumiceous soils that occur in many parts of the North Island (S.Chan, M.E.Thesis, University of Auckland, 1990). These properties are significantly different from those based on the international literature.

This work will incorporate this new data into analytical methods to evaluate seismic site response. Recently developed truly nonlinear methods (total and effective stress) will be used and these results compared with those obtained using current state of practice methods (equivalent linear techniques).

This project will use the recent data gathered on pumiceous soils, and would be complemented by the dynamic properties from the proposed project on the cyclic properties of pumiceous sands.

\section{GE 151Cyclic Properties of Pumiceous Sands Dept Civil Engineering, Auckland University - Prof $M$ $J$ Pender}

The engineering properties of sand deposits are important for the design of foundations especially in areas where earthquake loading is expected. The sands found in many parts of the North Island, particularly the Taupo Volcanic Zone, the Bay of Plenty, and other areas at least as far north as the mouth of the Waikato river, contain pumice which is compressible along with quartz which is very hard. The purpose of this research is to investigate the effect of pumice content on the compressibility, friction angle, cyclic stiffness and damping, pore pressure generation, and degradation of stiffness of NZ sands.

This information that will obtained has application to the understanding of site response and foundation behaviour under earthquake loading. Both of these are very sensitive to cyclic stiffness and damping of the materials in the soil profile and also to the generation of pore water pressure and cyclic degradation.

In addition the information from the project relates to the interpretation of penetration resistance. Much engineering design for sand deposits is based on penetration testing and the use of existing correlations to get properties of importance. The weakness of this approach is that these correlations have been derived in other countries usually for sand deposits having quartz as a dominant constituent. It is well known that penetration resistance is very sensitive to the compressibility of the sand.

Thus the project aims to obtain some benchmark property data on the properties of local sands, data which is currently not available but data which is of considerable interest to those members of the local geotechnical engineering community concerned with aseismic design.

SE 157 Significance of Elongation on the Seismic Resistance of Concrete Frame Structures Dept of Civil Engineering, Auckland University - Prof $R C$ Fenwick

The inelastic rotation in a plastic hinge zone of a reinforced concrete beam generates large tensile strains and small 
compressive strains, and consequently the zone elongates. The wedging action of aggregate particles in the cracks and the diagonal compression forces associated with shear also increase elongation. Test results show that plastic hinge zones in a ductile frame may each be expected to elongate by between 2 and 4 percent of the member depth when they sustain the magnitude of inelastic rotation expected in a major earthquake.

The total elongation of a beam at any one level can impose significant displacements on the external columns of a frame. Such displacements have important implications for the design of columns, beam column joints, support details for flooring and cladding elements, etc.

During the last 18 months the EQC sponsored research, by Ms. Douglas and Dr. Davidson, has lead to the development of a model of a plastic hinge zone, which enables elongation associated with flexural deformation to be predicted. Time history analyses of a 6 storey 3 bay frame, which develops uni-directional plastic hinges, have been made with a number of different ground motions. Elongations of the order of 150 mm were predicted (UASE Report No. 527 - Jan. 1993). Where reversing plastic hinge zones form, actions associated with shear are of major importance and these effects need to be incorporated into the model in the next stage of this research. Ms. Douglas plans to work on this aspect as part of her Ph.D. research programme.

SE 173 Moderate Earthquakes: An Assessment of the Cost Implications for

Modern Multistorey Buildings

Axiom Building Consultants - D Brunsdon

Recent moderate earthquakes overseas (Loma Prieta, Newcastle) have highlighted that the combined cost of direct damage and indirect disruption resulting from such events are much greater than generally anticipated. Furthermore, while the methodologies for obtaining Maximum Probable Loss estimates for facilities and buildings are relatively well established, the same cannot be said for the assessment of the cost implications of moderate earthquakes (as defined as Modified Mercalli VII \& VIII).
It is also considered that a change in the emphasis for earthquake preparedness from major earthquakes to moderate events would be beneficial in terms of instilling a greater sense of urgency in the business community.

This project is aimed at assessing the cost implications of repairing a modern building subjected to a moderate earthquake, and involves the following:

- Identifying an existing building constructed in the last decade (eg 5 to 8 storeys and of representative construction type), and obtaining the original drawings.

- Performing a brief structural analysis to determine the magnitude of building deformation in a moderate earthquake (using MM intensity/ground acceleration relationships).

- $\quad$ Assessing the probable resulting level of damage to non-structural elements such as glazing, lightweight cladding and partitioning, ceilings, plant and services items (including water damage resulting from sprinkler pipe rupture/activation), fixtures and fittings as well as structure itself.

- $\quad$ Estimating the cost of repairing this damage, along with the time implications and effects such as business interruption etc.

As part of this study, the basis of a methodology for carrying out such an assessment for any given building or facility would be developed and presented.

\section{PROJECT TO BE FUNDED WITHIN EQC's OWN BUDGET}

SE 171 Damage Ratios for Houses in the MM10 Zone of the 1931 Hawkes Bay Earthquake IGNS - D J Dowrick 